\title{
Frailty is Associated with Susceptibility to and Severity of Pneumonia in Functionally-independent Community- dwelling Older Adults: A JAGES Multilevel Cross- sectional Study
}

Kousuke Iwai-Saito ( $\sim$ anayoshi@med.niigata-u.ac.jp )

Division of International Health, Graduate School of Medical and Dental Sciences, Niigata University

\section{Yugo Shobugawa}

Department of Active Aging (donated by Tokamachi city, Niigata Japan), Graduate School of Medical and Dental Sciences, Niigata University

Jun Aida

Department of Oral Health Promotion, Graduate School of Medical and Dental Sciences, Tokyo Medical and Dental University

\section{Katsunori Kondo}

Department of Social Preventive Medical Sciences, Center for Preventive Medical Sciences, Chiba University

\section{Research Article}

Keywords: Pneumonia , mortality , infectious diseases, daily living, physical strength, nutrition status, oral function, homeboundness

Posted Date: January 27th, 2021

DOI: https://doi.org/10.21203/rs.3.rs-152951/v1

License: (c) (i) This work is licensed under a Creative Commons Attribution 4.0 International License. Read Full License

Version of Record: A version of this preprint was published at Scientific Reports on April 12th, 2021. See the published version at https://doi.org/10.1038/s41598-021-86854-3. 


\section{Abstract}

Pneumonia is a leading cause of mortality among older adults worldwide. Recently, several studies reported that frailty was associated with mortality among older adults hospitalized due to respiratory infectious diseases, including pneumonia. However, it is unknown whether frailty is associated with susceptibility to and severity of pneumonia in functionally-independent community-dwelling older adults. In this study, we examined whether frailty increased the susceptibility to pneumonia and hospitalization in older adults. We used cross-sectional data from the Japan Gerontological Evaluation Study; the data was collected by using mail-based, self-reported questionnaires from 177,991 functionally-independent community-dwelling older adults aged $\geq 65$ years. Our results showed that frailty was significantly associated with both occurrence of and hospitalization due to pneumonia after adjustments with covariates; (Preference ratio $\{$ PR $\} 1.92,95 \%$ confidence interval $\{95 \% \mathrm{Cl}\}[1.66$ 2.22] and $\mathrm{PR} 1.80,95 \% \mathrm{Cl}[1.42-2.28]$, respectively, $p<0.001$ for the both). Pre-frailty was associated only with the occurrence of pneumonia. Besides, the instrumental activity of daily living, physical strength, nutrition status, oral function, homeboundness, and depression status in frail older adults were associated with either or both occurrence of and hospitalization due to pneumonia. Our results suggest that frailty influenced the susceptibility to and severity of pneumonia in older adults.

\section{Introduction}

Pneumonia is a major cause of mortality and morbidity among older adults worldwide ${ }^{1}$. Community-acquired pneumonia (CAP) is a leading cause of morbidity among community-dwelling older adults in many countries and is different from hospital-acquired pneumonia (HAP) and ventilator-associated pneumonia (VAP). The overall incidence rates of CAP have been estimates as 1,790-4,000 in Japan, 2015; 630-1,463 in the U.S., 2015, and 1,400 in Europe, 2013 per 100,000 older adults aged $\geq 65$ years $^{2-4}$. A recent report showed that 6.8 million episodes of clinical pneumonia, including CAP, resulted in hospital admissions of older adults globally in 2015 .

Frailty is a state of increased vulnerability to stressors, including infectious diseases, which develops as a consequence of age-related decline in multiple physiological and psychological systems, including the central nervous, endocrine, skeletal muscle, and immune systems ${ }^{6,7}$. A recent report showed that the pooled prevalence rates of frail older adults in 62 countries were $22-26 \%$, based on the deficit accumulation model ${ }^{8}$. Several reports have recently shown that frailty was associated with increased severity and mortality of hospitalized older adults due to respiratory infectious diseases. He witt and colleagues showed that frailty in older adults hospitalized due to COVID-19 was associated with in-hospital mortality ${ }^{9}$. Lees and colleagues reported that the frailty of hospitalized older adults with influenza and acute respiratory illness was associated with lower odds of recovery 10. Luo and colleagues recently reported that frailty was associated with the severity of CAP and mortality among hospitalized older adults ${ }^{11}$. However, it was unknown whether frailty was related to the susceptibility to and severity of pneumonia among community-dwelling older adults.

Therefore, we examined whether frailty was associated with susceptibility to pneumonia and hospitalization among functionally-independent community-dwelling older adults aged $\geq 65$ years. We assessed associations between each physical or psychological condition in frailty and the prevalence and severity of pneumonia.

\section{Methods}




\section{Study sample}

The present study had a cross-sectional design and uses data from the Japan Gerontological Evaluation Study (JAGES). JAGES was designed to describe the health status and social determinants of people aged 65 years and older, without disabilities, and not eligible for the long-term care insurance (LTCI) in Japan. We used the data "JAGES 2016," which was obtained from self-reported questionnaires mailed to and filled-in by communitydwelling individuals in 39 municipalities in 2016. In the JAGES 2016 wave, self-administered questionnaires were mailed to functionally independent adults aged 65 years or older who did not receive benefits from the LTCI insurance in Japan. The survey was conducted in the municipalities between September 2016 and January 2017. The data included 180,021 individuals who answered the questionnaires with the basic items (response rate was $70.2 \%)$. Participants who did not answer questions regarding age or sex were excluded $(n=2,030)$. The data consisted of individuals who were not eligible for LTCI on $1^{\text {st }}$ April 2016. The data consisted of a three-stage hierarchal structure. The individual data were nested into 720 communities based on elementary or junior high school districts, and these communities were further nested into 39 municipalities.

\section{Outcome variables}

The occurrence of pneumonia and hospitalization due to it in the past year from September 2016 to January 2017 were the outcome variables. The occurrence of pneumonia was assessed by asking "Did you fall sick in the past year?" and instructing the participants to select an appropriate answer from the following items: "Influenza," "Pneumonia", and "none of them." Hospitalization due to pneumonia was assessed for participants who answered "Influenza" or "pneumonia" in the previous question by asking "If the sickness was due to influenza or pneumonia, were you hospitalized with relation to it?" and instructing the participants to select an answer from the following options: "Not hospitalized," "Hospitalized due to influenza," "Hospitalized due to pneumonia," "Contracted influenza while I was hospitalized for other diseases," and "Developed pneumonia while I was hospitalized for other diseases." Only participants who answered "Hospitalized due to pneumonia" were considered to be hospitalized. The participants who answered "Influenza" in the first question and "Hospitalized due to pneumonia" in the second were included because influenza can cause primary viral or secondary bacterial pneumonia ${ }^{12}$.

\section{Frailty}

Frailty was assessed using the Kihon Check List $(\mathrm{KCL})^{13}$. KCL was developed by the Japanese Ministry of Health, Labor and Welfare to identify older adults requiring LTCI. KCL was included in the self-administered questionnaires of the JAGES 2016 wave. KCL consists of 25 questions classified into the following seven categories: instrumental activity of daily living (IADL), physical strength, nutritional status, oral function, homeboundness, cognitive function, and depressive mood (Supplemental Table 1). The scores from the KCL was well correlated with the validated assessments of physical strength, nutritional state, cognitive function, depressive mood, and the number of frailty phenotypes defined by the Cardiovascular Health Study criteria (CHS) 13. Frailty was categorized into three groups based on KCL scores: robust, 0-3; pre-frail, 4-7; and frail, $\geq 8$; scores were calculated from the KCL questions, which were validated with the pre-frail and frail categories established by the $\mathrm{CHS}$ criteria ${ }^{13}$. KCL variables were generated for each of the seven categories. Each KCL variable was 
categorized into three groups, based on answers to questions: 0 , not applicable; 1 , applicable; and 2 or $\geq 2$ applicable.

\section{Covariates}

Age was classified into two groups (65-74 years and $\geq 75$ years). Educational attainment was categorized into five groups: $<6$ years, 6-9 years, 10-12 years, $\geq 13$ years, and others. Equalized income was calculated by dividing the normalized household gross income in 2015 by the square root of the number of household members, and was categorized into five groups: < 0.5, 0.50-0.99, 1.00-1.99, 2.00-3.99, and $\geq 4.00$ million yen. The household structure was assessed by asking the respondents the question, "Who do you live with?". They were asked to choose from the following options: "no one," "spouse," "son," "daughter," "spouse of child," "grandchild," "brother or sister, "father," "mother," "father-in-law," "mother-in-law," and "other." The responses were classified into six groups as follows: living alone, living with a spouse, living with children, living with a spouse and children, living in three-generation households (living with/without a spouse, but with one of the sons/daughters/son's or daughter's spouse and grandchildren), and the in a household structure other than the above five categories. Marital status was assessed by asking, "What is your marital status?" and participants were instructed to select one from the following five options: "Married," "Widowed," "Divorced," "Never married" and "Other." Smoking status was assessed by asking, "Do you smoke cigarettes?" and the participants were instructed to select appropriate answers from the following items: "Never smoked," "Quit smoking $\geq 5$ years ago", "Quit smoking < 5 years ago," "Smoke sometimes" and "Smoke almost every day." The population density of the municipality was categorized as follows: metropolitan (density over 4,000 people per km²), urban (density between 1,500 and 4,000 people per $\mathrm{km}^{2}$ ), semi-urban (density between 1,000 and 1,499 people per $\mathrm{km}^{2}$ ), and rural (density below 1,000 people per $\mathrm{km}^{2}$ ) ${ }^{14}$. A municipality dummy variable was generated to adjust for differences in municipalities' policies in preventing frailty ${ }^{15}$. The diabetes, respiratory, heart, kidney/prostate gland, hematological, or immune disease status was assessed by asking participants whether they were receiving any treatment or experiencing after-effects of any of the above diseases. Pneumococcal vaccination status was assessed by asking the participants, "Did you get a pneumococcal vaccination in the last five years? They chose from the following options: "No," "Yes, I got vaccinated using my municipality's subsidy", and "Yes, but I did not get vaccinated using my municipality's subsidy". The participants who chose the two latter options were categorized as vaccinated.

\section{Statistical analysis}

Multilevel Poisson regression analyses with random intercepts were performed to assess associations between frailty and pneumonia/hospitalization after adjusting for all the covariates. The data were structured in three levels: the individuals were nested within their elementary or junior high school districts and the districts were further nested within the municipalities. The covariates consist of all the covariates at individual-level and the municipality dummy variable used to adjust for differences in municipalities' policies in older adult's health including preventing frailty and pneumonia at municipality-level ${ }^{15,16}$. The individual-level covariates were: age group, sex, educational attainment, equivalized income, household structure, marital status, smoking status, municipality population density, diabetes, respiratory disease, heart disease, kidney/prostate gland disease, hematological/immune disease, and pneumococcal vaccination. The prevalence ratios (PRs) and 95\% confidence 
intervals (95\% Cls) were calculated after adjusting for all covariates. We used Stata version 14.2 (StataCorp., College Station, TX, USA) for all analyses, with a 2-tailed significance level set at $5 \%$.

\section{Ethical consideration}

The process of obtaining informed consent in the present study was as follows: the questionnaire was sent by mail with the explanation of the study; the participants read the written explanation about the purpose of study and replied. Hence, we considered that informed consent was provided by those who replied and sent back the questionnaire. The JAGES protocol in 2016 was approved by the ethics committee of National Center for Geriatrics and Gerontology (No. 992) and the ethics committee of Chiba University (No. 2493). We followed the STROBE Statement to report our observational study. This study was performed in accordance with the principles of the Declaration of Helsinki. Informed consent was obtained from all participants.

\section{Results}

\section{The relationship between prevalence rates of pneumonia and hospitalization with frailty and other characteristics of older adults}

Table 1 compares the prevalence rates of pneumonia in the past year with the characteristics of communitydwelling older adults. Frail and pre-frail older adults were 3- and 1.5-times, respectively, more likely to contract pneumonia than non-frail adults. Older adults, with $\geq 1$ applicable question in KCL related to IADL, physical strength, nutrition status, oral function, homeboundness, cognitive function, and depression status, were likely to contract pneumonia than those with a score $=0$ (none of the questions were applicable). Older adults aged $\geq 75$ years, who were male, had lower education/income, who lived in three-generation households, had "other" marital status, who had quit smoking $<5$ years ago, and who lived in rural or semi-urban areas were more likely to contract pneumonia than those in other categories. Older adults with diabetes, respiratory, heart, kidney/prostate gland, and hematological/immune diseases, and those who received pneumococcal vaccination were more likely to contract pneumonia more than those without any disease. 
Table 1

Prevalence rates of pneumonia in comparison with the characteristics of older adults

\begin{tabular}{|c|c|c|c|c|c|c|c|}
\hline Variable & Category & Number & $\begin{array}{l}\text { PR } \\
(\%)\end{array}$ & Variables & Category & Number & $\begin{array}{l}\text { PR } \\
(\%)\end{array}$ \\
\hline \multirow[t]{3}{*}{ Frailty } & Non-frail & 46103 & 1.0 & \multirow{6}{*}{$\begin{array}{l}\text { Household structure } \\
\text { (Living alone or with } \\
\text { family) }\end{array}$} & Alone & 17960 & 1.6 \\
\hline & Pre-frail & 74226 & 1.5 & & With spouse & 76735 & 1.7 \\
\hline & Frail & 27826 & 3.0 & & $\begin{array}{l}\text { With } \\
\text { children }\end{array}$ & 13484 & 1.7 \\
\hline \multirow[t]{3}{*}{ IADL } & 0 * & 93053 & 1.4 & & $\begin{array}{l}\text { With spouse } \\
\text { and children }\end{array}$ & 25782 & 1.6 \\
\hline & 1 & 48447 & 1.7 & & $\begin{array}{l}\text { In a three- } \\
\text { generation } \\
\text { household }\end{array}$ & 20935 & 1.9 \\
\hline & $\geq 2$ & 30470 & 2.3 & & Others & 25095 & 1.6 \\
\hline \multirow{3}{*}{$\begin{array}{l}\text { Physical } \\
\text { strength }\end{array}$} & 0 & 81729 & 1.3 & \multirow[t]{5}{*}{ Marital status } & Married & 127198 & 1.7 \\
\hline & 1 & 50748 & 1.7 & & Widowed & 35437 & 1.6 \\
\hline & $\geq 2$ & 38648 & 2.4 & & Divorced & 7995 & 1.7 \\
\hline \multirow[t]{3}{*}{ Nutrition status } & 0 & 141534 & 1.4 & & $\begin{array}{l}\text { Never } \\
\text { married }\end{array}$ & 5272 & 1.3 \\
\hline & 1 & 31089 & 2.7 & & Others & 1328 & 3.1 \\
\hline & 2 & 2885 & 5.7 & \multirow[t]{5}{*}{ Smoking status } & $\begin{array}{l}\text { Never } \\
\text { smoked }\end{array}$ & 106724 & 1.3 \\
\hline \multirow[t]{3}{*}{ Oral function } & 0 & 93575 & 1.2 & & $\begin{array}{l}\text { Quit } \\
\text { smoking } \geq 5 \\
\text { years ago }\end{array}$ & 44794 & 2.3 \\
\hline & 1 & 50797 & 1.8 & & $\begin{array}{l}\text { Quit } \\
\text { smoking }<5 \\
\text { years ago }\end{array}$ & 5800 & 4.0 \\
\hline & $\geq 2$ & 30043 & 2.8 & & $\begin{array}{l}\text { Smoking } \\
\text { sometimes }\end{array}$ & 2821 & 2.0 \\
\hline \multirow[t]{3}{*}{ Homeboundness } & 0 & 143613 & 1.4 & & $\begin{array}{l}\text { Smoking } \\
\text { almost every } \\
\text { day }\end{array}$ & 16230 & 1.2 \\
\hline & 1 & 29376 & 2.6 & \multirow{4}{*}{$\begin{array}{l}\text { Municipality Population } \\
\text { density }\end{array}$} & Metropolitan & 58881 & 1.7 \\
\hline & 2 & 3972 & 4.1 & & Urban & 48294 & 1.5 \\
\hline \multirow{2}{*}{$\begin{array}{l}\text { Cognitive } \\
\text { function }\end{array}$} & 0 & 115270 & 1.5 & & Semi-urban & 18071 & 1.8 \\
\hline & 1 & 44923 & 1.9 & & Rural & 54745 & 1.8 \\
\hline
\end{tabular}

*Numbers in IADL, physical strength, nutrition status, oral function, homebound, cognitive function, depressive mode are the numbers of the applicable KCL questions for the older adults.

PR, prevalence rate; IADL, instrumental activity of daily living; KCL, Kihon checklist. 


\begin{tabular}{|c|c|c|c|c|c|c|c|}
\hline Variable & Category & Number & $\begin{array}{l}\text { PR } \\
(\%)\end{array}$ & Variables & Category & Number & $\begin{array}{l}\text { PR } \\
(\%)\end{array}$ \\
\hline & $\geq 2$ & 15224 & 2.6 & \multirow[t]{2}{*}{ Diabetes } & No & 148495 & 1.6 \\
\hline \multirow{3}{*}{$\begin{array}{l}\text { Depression } \\
\text { status }\end{array}$} & 0 & 99421 & 1.2 & & Yes & 22991 & 2.1 \\
\hline & 1 & 28866 & 1.8 & \multirow[t]{2}{*}{ Respiratory disease } & No & 162577 & 1.1 \\
\hline & $\geq 2$ & 37415 & 2.6 & & Yes & 8909 & 12.9 \\
\hline \multirow[t]{2}{*}{ Age groups } & $65-74$ & 101025 & 1.4 & \multirow[t]{2}{*}{ Heart disease } & No & 154312 & 1.6 \\
\hline & $\geq 75$ & 78966 & 2.1 & & Yes & 17174 & 3.0 \\
\hline \multirow[t]{2}{*}{ Sex } & Male & 82257 & 2.1 & \multirow{2}{*}{$\begin{array}{l}\text { Kidney/Prostate gland } \\
\text { disease }\end{array}$} & No & 158970 & 1.6 \\
\hline & Female & 97734 & 1.3 & & Yes & 12516 & 2.6 \\
\hline \multirow{5}{*}{$\begin{array}{l}\text { Educational } \\
\text { attainment }\end{array}$} & $>6$ & 1723 & 2.8 & \multirow{2}{*}{$\begin{array}{l}\text { Hematological/Immune } \\
\text { disease }\end{array}$} & No & 169260 & 1.7 \\
\hline & $6-9$ & 57731 & 1.8 & & Yes & 2226 & 4.0 \\
\hline & $10-12$ & 72100 & 1.6 & \multirow{2}{*}{$\begin{array}{l}\text { Pneumococcal } \\
\text { vaccination }\end{array}$} & No & 94509 & 1.1 \\
\hline & $\geq 13$ & 45388 & 1.5 & & Yes & 72274 & 2.5 \\
\hline & $\begin{array}{l}\text { The } \\
\text { other }\end{array}$ & 1117 & 2.1 & & & & \\
\hline \multirow{5}{*}{$\begin{array}{l}\text { Equivalized } \\
\text { income, million } \\
\text { yen }\end{array}$} & $<0.5$ & 6996 & 1.8 & & & & \\
\hline & $\begin{array}{l}0.50- \\
0.99\end{array}$ & 18547 & 1.7 & & & & \\
\hline & $\begin{array}{l}1.00- \\
1.99\end{array}$ & 47711 & 1.6 & & & & \\
\hline & $\begin{array}{l}2.00- \\
3.99\end{array}$ & 43949 & 1.6 & & & & \\
\hline & $\geq 4.00$ & 19882 & 1.5 & & & & \\
\hline \multicolumn{8}{|c|}{$\begin{array}{l}\text { *Numbers in IADL, physical strength, nutrition status, oral function, homebound, cognitive function, depressive } \\
\text { mode are the numbers of the applicable KCL questions for the older adults. }\end{array}$} \\
\hline
\end{tabular}

Table 2 compares the prevalence rates of hospitalization due to pneumonia with the characteristics of older adults. Frail and pre-frail older adults were 3.3- and 1.6-times, respectively, more likely to be hospitalized than nonfrail adults. Older adults, with $\geq 1$ applicable question in $\mathrm{KCL}$ from all the seven categories were more likely to be hospitalized than those with a score $=0$ (none of the questions were applicable). Older adults aged $\geq 75$, who were male, had lower education/income, who lived in three-generation households, had "other" marital status, who had quit smoking $<5$ years ago, and who lived in rural areas were more likely to be hospitalized than those in other categories. Older adults with diabetes, respiratory, heart, kidney/prostate gland, and hematological/immune diseases and who received pneumococcal vaccination were more likely to be hospitalized than those without any disease. 
Table 2

Prevalence rates of hospitalization due to pneumonia in comparison with the characteristics of older adults

\begin{tabular}{|c|c|c|c|c|c|c|c|}
\hline Variable & Category & Number & $\begin{array}{l}\text { PR } \\
(\%)\end{array}$ & Variables & Category & Number & $\begin{array}{l}\text { PR } \\
(\%)\end{array}$ \\
\hline \multirow[t]{3}{*}{ Frailty } & Non-frail & 1993 & 7.7 & \multirow{6}{*}{$\begin{array}{l}\text { Household } \\
\text { structure } \\
\text { (Living alone or } \\
\text { with family) }\end{array}$} & Alone & 784 & 14.9 \\
\hline & Pre-frail & 3580 & 12.7 & & With spouse & 3833 & 14.8 \\
\hline & Frail & 1692 & 25.1 & & With children & 579 & 13.6 \\
\hline \multirow[t]{3}{*}{ IADL } & $0 *$ & 4483 & 11.4 & & $\begin{array}{l}\text { With spouse } \\
\text { and children }\end{array}$ & 1220 & 14.8 \\
\hline & 1 & 2352 & 15.3 & & $\begin{array}{l}\text { In a three- } \\
\text { generation } \\
\text { household }\end{array}$ & 1126 & 16.6 \\
\hline & $\geq 2$ & 1516 & 23.6 & & Others & 1140 & 16.4 \\
\hline \multirow[t]{3}{*}{ Physical strength } & 0 & 3701 & 11.1 & \multirow[t]{5}{*}{ Marital status } & Married & 6399 & 14.9 \\
\hline & 1 & 2475 & 13.1 & & Widowed & 1497 & 16.1 \\
\hline & $\geq 2$ & 2125 & 23.6 & & Divorced & 397 & 13.9 \\
\hline \multirow[t]{3}{*}{ Nutrition status } & 0 & 6498 & 12.2 & & Never married & 217 & 11.1 \\
\hline & 1 & 1777 & 22.0 & & Others & 68 & 29.4 \\
\hline & 2 & 223 & 38.6 & \multirow[t]{5}{*}{ Smoking status } & Never smoked & 4748 & 11.3 \\
\hline \multirow[t]{3}{*}{ Oral function } & 0 & 3934 & 11.9 & & $\begin{array}{l}\text { Quit smoking } \geq \\
5 \text { years ago }\end{array}$ & 2546 & 19.5 \\
\hline & 1 & 2584 & 14.9 & & $\begin{array}{l}\text { Quit smoking < } \\
5 \text { years ago }\end{array}$ & 384 & 36.2 \\
\hline & $\geq 2$ & 1881 & 21.4 & & $\begin{array}{l}\text { Smoking } \\
\text { sometimes }\end{array}$ & 155 & 19.4 \\
\hline \multirow[t]{3}{*}{ Homeboundness } & 0 & 6733 & 12.2 & & $\begin{array}{l}\text { Smoking } \\
\text { almost every } \\
\text { day }\end{array}$ & 687 & 10.8 \\
\hline & 1 & 1569 & 22.8 & \multirow{4}{*}{$\begin{array}{l}\text { Population } \\
\text { density }\end{array}$} & Metropolitan & 2840 & 14.1 \\
\hline & 2 & 249 & 41.4 & & Urban & 2263 & 14.5 \\
\hline \multirow[t]{3}{*}{ Cognitive function } & 0 & 5320 & 13.7 & & Semi-urban & 926 & 14.9 \\
\hline & 1 & 2284 & 16.0 & & Rural & 2653 & 17.1 \\
\hline & $\geq 2$ & 883 & 21.2 & \multirow[t]{2}{*}{ Diabetes } & No & 7200 & 14.8 \\
\hline Depression status & 0 & 4458 & 11.1 & & Yes & 1178 & 19.2 \\
\hline
\end{tabular}

*Numbers in IADL, physical strength, nutrition status, oral function, homebound, cognitive function, depressive mode indicate how many of the KCL questions were applicable to older adults.

PR, prevalence rate; IADL, instrumental activity of daily living; KCL, Kihon checklist. 


\begin{tabular}{|c|c|c|c|c|c|c|c|}
\hline Variable & Category & Number & $\begin{array}{l}\mathrm{PR} \\
(\%)\end{array}$ & Variables & Category & Number & $\begin{array}{l}\text { PR } \\
(\%)\end{array}$ \\
\hline & 1 & 1453 & 14.3 & \multirow{2}{*}{$\begin{array}{l}\text { Respiratory } \\
\text { disease }\end{array}$} & No & 6989 & 10.1 \\
\hline & $\geq 2$ & 2155 & 22.7 & & Yes & 1389 & 42.1 \\
\hline \multirow[t]{2}{*}{ Age groups } & $65-74$ & 5020 & 10.4 & \multirow[t]{2}{*}{ Heart disease } & No & 7293 & 14.1 \\
\hline & $\geq 75$ & 3662 & 21.8 & & Yes & 1085 & 24.3 \\
\hline \multirow[t]{2}{*}{ Sex } & Male & 4402 & 19.3 & \multirow{2}{*}{$\begin{array}{l}\text { Kidney/Prostate } \\
\text { gland disease }\end{array}$} & No & 7608 & 14.7 \\
\hline & Female & 4280 & 11.0 & & Yes & 770 & 22.5 \\
\hline \multirow{5}{*}{$\begin{array}{l}\text { Educational } \\
\text { attainment }\end{array}$} & $>6$ & 76 & 32.9 & \multirow{2}{*}{$\begin{array}{l}\text { Hematological/ } \\
\text { Immune disease }\end{array}$} & No & 8213 & 15.3 \\
\hline & $6-9$ & 2678 & 20.4 & & Yes & 165 & 22.4 \\
\hline & $10-12$ & 3492 & 13.1 & \multirow{2}{*}{$\begin{array}{l}\text { Pneumococcal } \\
\text { vaccination }\end{array}$} & No & 4296 & 10.5 \\
\hline & $\geq 13$ & 2296 & 11.8 & & Yes & 4181 & 19.1 \\
\hline & $\begin{array}{l}\text { The } \\
\text { other }\end{array}$ & 67 & 11.9 & & & & \\
\hline \multirow{5}{*}{$\begin{array}{l}\text { Equivalized } \\
\text { income, million } \\
\text { yen }\end{array}$} & $<0.5$ & 357 & 15.1 & & & & \\
\hline & $\begin{array}{l}0.50- \\
0.99\end{array}$ & 876 & 13.6 & & & & \\
\hline & $\begin{array}{l}1.00- \\
1.99\end{array}$ & 2294 & 14.5 & & & & \\
\hline & $\begin{array}{l}2.00- \\
3.99\end{array}$ & 2146 & 14.9 & & & & \\
\hline & $\geq 4.00$ & 930 & 13.9 & & & & \\
\hline \multicolumn{8}{|c|}{$\begin{array}{l}\text { *Numbers in IADL, physical strength, nutrition status, oral function, homebound, cognitive function, depressive } \\
\text { mode indicate how many of the KCL questions were applicable to older adults. }\end{array}$} \\
\hline
\end{tabular}

\section{Frailty was associated with susceptibility to and severity of pneumonia among community-dwelling older adults.}

Table 3 shows PR and $95 \% \mathrm{Cl}$ of the association between frailty and the occurrence of pneumonia in the past year or hospitalization due to pneumonia among the community-dwelling older adults. After adjusting with all the covariates, frailty in older adults was significantly associated with both occurrence of and hospitalization due to pneumonia compared to non-frailty (PR 1.92 [95\% Cl 1.66-2.22] and PR 1.80 [95\% Cl 1.42-2.28], respectively, $\mathrm{p}<$ 0.001 for the both). Pre-frailty was also significantly associated with the occurrence of pneumonia but not with hospitalization, compared to non-frailty (PR 1.30 [95\% Cl 1.14-1.48, p< 0.001] and PR 1.23 [95\% Cl 0.98-1.53], respectively). 
Table 3

Prevalence ratios (PR) and 95\% confidence intervals (95\% Cls) between the occurrence of or hospitalization due to pneumonia and frailty among the community-dwelling older adults

\begin{tabular}{|lllll|}
\hline \multicolumn{3}{|c|}{ Pneumonia } & \multicolumn{3}{l|}{ The hospitalization } \\
\hline & PR & $95 \% \mathrm{Cl}$ & PR & $95 \% \mathrm{Cl}$ \\
\hline Non-frail & 1.00 & Reference & 1.00 & Reference \\
\hline Pre-frail & $1.30^{\star \star \star}$ & $1.14-1.48$ & 1.23 & $0.98-1.53$ \\
\hline Frail & $1.92^{\star \star \star}$ & $1.66-2.22$ & $1.80 \star \star \star$ & $1.42-2.28$ \\
\hline $\begin{array}{l}\text { The PRs and } 95 \% \mathrm{Cl} \text { were adjusted for all the covariates in the multilevel Poisson regression with random } \\
\text { intercepts. } * \star \mathrm{p}<0.001\end{array}$ & & & \\
\hline
\end{tabular}

\section{Associations between each of the KCL categories and pneumonia/hospitalization among community-dwelling older adults}

Table 4 shows PRs and 95\% Cls of associations between each of the KCL categories and the occurrence of or hospitalization due to pneumonia in the past year. After adjusting with all the other KCL categories and covariates, the lower and lowest IADL ( $\geq 1$ and $\geq 2 \mathrm{KCL}$ questions were applicable) were negatively associated with the occurrence of pneumonia (PR 0.90, 95\% Cl [0.84-0.97], p<0.01 and PR 0.79, 95\% Cl [0.72-0.86],p< 0.001, respectively) and the lowest was associated with hospitalization in older adults (PR 1.24, 95\% Cl [1.011.53], $\mathrm{p}<0.05)$. The lowest physical strength was associated with both occurrence of and hospitalization due to pneumonia in older adults (PR 1.12, 95\% Cl [1.03-1.22] and PR 1.32, 95\% Cl [1.07-1.64]), respectively, $\mathrm{p}<0.01$ for the both). The lower nutrition status was associated with both occurrence of and hospitalization due to pneumonia (PR 1.09, 95\% Cl [1.004-1.14], p<0.05 and PR 1.54, 95\% Cl [1.30-1.82], p < 0.001, respectively), and the lowest was associated only with hospitalization in older adults (PR 1.71, 95\% $\mathrm{Cl}[1.25-2.34], \mathrm{p}<0.01)$. The lower and lowest oral function were associated with the occurrence of pneumonia in older adults (PR $1.18,95 \% \mathrm{Cl}$ [1.10 - 1.27] and PR 1.27, 95\% Cl [1.17 - 1.39], respectively, $p<0.001$ for the both). The worst case ( $\geq 2 \mathrm{KCL}$ questions were applicable) of homeboundness was associated with hospitalization in older adults (PR 1.60, 95\% $\mathrm{Cl}[1.11-2.12], \mathrm{p}<0.05)$. The worse and worst cases of depression were associated with the occurrence of pneumonia in older adults (PR 1.10, 95\% Cl [1.006 - 1.19], $\mathrm{p}<0.05$ and PR 1.13, 95\% $\mathrm{Cl}[1.04-1.23], \mathrm{p}<0.01$, respectively). 
Table 4

Prevalence ratios (PR) and 95\% confidence intervals (95\% Cls) of associations between the occurrence of/hospitalization due to pneumonia and each of the KCL categories in community-dwelling older adults

\section{Occurrence of pneumonia}

$\begin{array}{lllll}\text { IADL } & \text { PR } & 95 \% \mathrm{Cl} & \mathrm{PR} & 95 \% \mathrm{Cl} \\ 0 & 1.00 & \text { Reference } & 1.00 & \text { Reference } \\ 1 & 0.90 \star \star & 0.84-0.97 & 1.11 & 0.93-1.34 \\ \geq 2 & 0.79 \star \star \star & 0.72-0.86 & 1.24^{\star} & 1.01-1.53\end{array}$

Physical strength

$\begin{array}{lllll}0 & 1.00 & \text { Reference } & 1.00 & \text { Reference } \\ 1 & 1.03 & 0.96-1.10 & 1.07 & 0.88-1.29 \\ \geq 2 & 1.12^{\star *} & 1.03-1.22 & 1.32 * \star & 1.07-1.64\end{array}$

Nutrition status

\begin{tabular}{|lllll}
0 & 1.00 & Reference & 1.00 & Reference \\
\hline 1 & $1.09 *$ & $1.004-1.17$ & $1.54 \star \star \star$ & $1.30-1.82$ \\
\hline 2 & 0.94 & $0.73-1.21$ & $1.71^{\star \star}$ & $1.25-2.34$
\end{tabular}

Oral function

$\begin{array}{lllll}0 & 1.00 & \text { Reference } & 1.00 & \text { Reference } \\ 1 & 1.18 * \star \star & 1.10-1.27 & 1.01 & 0.84-1.21 \\ \geq 2 & 1.27 \star \star \star & 1.17-1.39 & 0.85 & 0.69-1.05\end{array}$

Homeboundness

$\begin{array}{lllll}0 & 1.00 & \text { Reference } & 1.00 & \text { Reference } \\ 1 & 0.97 & 0.89-1.06 & 1.09 & 0.90-1.33 \\ 2 & 0.86 & 0.67-1.09 & 1.60 * & 1.11-2.12\end{array}$

Cognitive function

$\begin{array}{lllll}0 & 1.00 & \text { Reference } & 1.00 & \text { Reference } \\ 1 & 1.06 & 0.99-1.14 & 0.97 & 0.82-1.16 \\ \geq 2 & 1.12 & 0.99-1.25 & 0.92 & 0.72-1.18\end{array}$

Depression status

The KCL and other variables were inputs for the multilevel Poisson regression with random intercepts. Numbers in KCL scores represent how many questions were applicable to older adults.

${ }^{*} p<0.05,{ }^{* *} p<0.01, * * * p<0.001$

IADL, instrumental activity of daily living; KCL, Kihon checklist. 


\begin{tabular}{|c|c|c|c|c|}
\hline \multirow[b]{2}{*}{0} & \multicolumn{2}{|c|}{ Occurrence of pneumonia } & \multicolumn{2}{|c|}{ Hospitalization due to pneumonia } \\
\hline & 1.00 & Reference & 1.00 & Reference \\
\hline 1 & $1.10^{*}$ & $1.006-1.19$ & 1.01 & $0.81-1.25$ \\
\hline$\geq 2$ & $1.13^{\star \star}$ & $1.04-1.23$ & 1.05 & $0.87-1.28$ \\
\hline \multicolumn{5}{|c|}{$\begin{array}{l}\text { The KCL and other variables were inputs for the multilevel Poisson regression with random intercept } \\
\text { Numbers in KCL scores represent how many questions were applicable to older adults. }\end{array}$} \\
\hline \multicolumn{5}{|c|}{${ }^{\star} \mathrm{p}<0.05, * \star \mathrm{p}<0.01, * \star \star p<0.001$} \\
\hline IADL & of daily & KL, Kihon che & & \\
\hline
\end{tabular}

\section{Discussion}

We examined whether frailty was associated with the occurrence of and hospitalization due to pneumonia compared to non-frailty in community-dwelling older adults. Our analysis showed that frailty was significantly associated with both occurrence of and hospitalization due to pneumonia after adjusting for all covariates (Table 3). Besides, IADL, physical strength, nutrition status, oral function, homeboundness, and depression status were associated with either or both of them (Table 4). Our results also suggested that frailty was associated with both susceptibility to and severity of pneumonia, and the six physical or psychological conditions in frailty were associated with either or both of them in community-dwelling older adults.

Several reports have recently shown that frailty was related to mortality in older adults hospitalized due to respiratory infectious diseases ${ }^{9-11}$. However, it is unknown whether frailty is associated with susceptibility to and severity of pneumonia in community-dwelling older adults. Our results showed that frailty was associated with both occurrence of and hospitalization due to pneumonia in community-dwelling older adults, suggesting that frailty was associated with susceptibility to and severity of pneumonia in these adults (Table 3). Therefore, our results indicate the possibility that frailty may be one of the risk factors related to CAP and hospitalization in community-dwelling older adults. The pneumonia cases were likely CAP because HAP and VAP were excluded by asking corresponding questions to the participants (see "Outcome variables" in Methods). Our results also suggest that frailty may be an important indicator in the prevention of pneumonia among community-dwelling older adults, not only be an indicator of the mortality in older adults hospitalized for pneumonia as recently reported ${ }^{11}$.

Our results showed that low IADL was negatively associated with pneumonia after adjusting for all other KCL categories and covariates (Table 4). However, a negative association between low IADL and pneumonia has not been reported so far. Several reports have shown that community-dwelling older adults with low IADL are less social than those with normal IADL ${ }^{17-19}$. Social participation was reported to be associated with influenza among community-dwelling older adults ${ }^{20}$. Taken together, low IADL may present fewer opportunities for infection with respiratory infectious pathogens. However, our results showed that the lowest IADL was associated with hospitalization among older adults (Table 4). Reichard and colleagues reported that adults with low IADL delayed or forewent receiving healthcare services twice more often than those with normal IADL, even if they were insured ${ }^{21}$. Older adults with the lowest IADL may have done the same when compared to those with normal IADL; 
they might have delayed visiting the physician even if they had perceived subjective symptoms of pneumonia and hence, the symptoms may have worsened and become more severe leading to hospitalization.

The decline in immune function, so-called "immune senescence", occurs in frail older adults; this is associated with the malfunction of the cellular and humoral immune systems ${ }^{6,22}$. Several research groups have reported that antibodies against influenza were more prevalent in physically active older adults than in sedentary individuals after vaccination; exercise enhanced the production of immunoglobulin A $(\lg A)$ secreted by the salivary gland in adults aged $\geq 65^{23-25}$. IgA is important for mucosal immunity as frontline protection against infections. Our results showed that the lowest physical strength was associated with both occurrence of and hospitalization due to pneumonia (Table 4). Older adults with the lowest physical strength may be more susceptible to infections by pneumonia-causing pathogens due to decreased immunity, including the poor secretion of $\lg A$; this may enable pathogens to invade the upper and lower respiratory tracts causing pneumonia and subsequent hospitalization.

Beard and the colleagues reported that iron deficiency was common among homebound older adults and it was associated with the impairment of cellular and innate immunities ${ }^{26}$. However, the relationship between older adults' homebound status and the prevalence of pneumonia has not been investigated before. Our results showed that the worst case of homeboundness was associated with hospitalization (Table 4). Impairment of immunity may increase the severity of pneumonia and subsequent hospitalization among homebound older adults.

Several reports have already shown that poor nutrition is associated with CAP and hospitalization ${ }^{27-29}$. The decline in oral function, including poor swallowing and cough reflex, causes dysphagia, which induces aspiration pneumonia in frail older adults ${ }^{4,30-33}$. Geriatric depression is associated with the malfunction of the immune system and increased susceptibility to infection ${ }^{34-36}$. Our results showed that the nutrition status, oral function, and depression status were associated with either or both occurrence of and hospitalization due to pneumonia (Table 4). The concordance between our results and the reported studies on the associations between poor conditions and infectious diseases, including pneumonia, suggests that frailty is associated with susceptibility to pneumonia or hospitalization.

Our study has some limitations. First, this study has a cross-sectional design. Therefore, the possibility of pneumonia causing frailty cannot be completely excluded. However, the prevalence rate of pneumonia was $3.0 \%$ among all frail older adults (Table 1). Second, the occurrence of and hospitalization due to pneumonia were selfreported by the participants and not collected from medical records from the physicians in-charge. However, it is unlikely that they arbitrarily diagnosed themselves with pneumonia or non-medical professionals did so and they trusted it because most Japanese citizens have good medical access due to the national health coverage ${ }^{37}$. Third, we did not categorize the medical records based on the type of pneumonia, for example, CAP, HAP, or VAP. However, we expect most cases to be CAP because we excluded cases of nosocomial pneumonia with a question (see Methods). Besides, all the participants were functionally-independent community-dwelling older adults, not eligible for Japan's LTCI.

\section{Conclusion}

It was unknown whether frailty was associated with the susceptibility to and severity of pneumonia among community-dwelling older adults, although recent reports have shown that it is related to mortality due to respiratory infectious diseases in hospitalized older adults. We examined whether frailty was associated with the 
occurrence of and hospitalization due to pneumonia in functionally-independent community-dwelling older adults. Our results showed that frailty was significantly associated with both occurrence of and hospitalization due to pneumonia after adjusting for all covariates. Our results showed that the IADL, physical strength, nutrition status, oral function, homeboundness, and depression status in frail older adults were significantly associated with either or both. Our results suggested that frailty was associated with susceptibility to and severity of pneumonia, which is a leading cause of mortality and morbidity among community-dwelling older adults worldwide. This study showed frailty as a risk factor for increased susceptibility to and severity of pneumonia among community-dwelling older adults. It is necessary to assess whether frailty is also significantly associated with CAP diagnosed by medical doctors and the causal relationship between frailty and pneumonia should be confirmed in longitudinal studies in the future.

\section{Declarations}

\section{Data availability}

All data needed to evaluate the conclusions in the paper are presented in the paper and/or the Supplementary Material. The JAGES data used in this study will be made available upon request-the authors require the applicant to submit an analysis proposal that will be reviewed by an internal JAGES committee to avoid duplication. Confidentiality concerns prevent us from depositing our data in a public repository. Proposals submitted by outside investigators will be discussed during the monthly investigators' meeting to ensure that there is no overlap with ongoing analyses. If approval to access the data is granted, the JAGES researchers will request the outside investigator to financially support the data manager for the time he/she requires to prepare the data for outside use.

\section{Acknowledgments}

This study used data from JAGES, which was conducted by the Nihon Fukushi University Center for Well-being and Society. We gratefully appreciate all participants who generously spent time and collaborated in that study. This work was supported by the Japan Science and Technology Agency-Supported Program on Open Innovation Platform with Enterprises, Research Institute and Academia (Grant no JPMJOP1831; Development issue no. 5). We thank Dr. Atsuo Amano, Department of Preventive Dentistry, Graduate School of Dentistry, Osaka University, Japan for his helpful comments on the preparation of this manuscript. We thank Editage (www.editage.com) for English language editing.

\section{Author contributions}

All authors contributed to the study conception and design. Material preparation, data collection, and analysis were performed by KS and YS. The first draft of the manuscript was written by KS and YS. JA and KK prepared the subsequent versions of the manuscript. All authors have read and approved the final manuscript.

\section{Conflict of Interest}

The authors declare that they have no conflict of interest. 


\section{Funding}

This study used data from JAGES. The present study was supported by Grant-in-Aid for Scientific Research (15H01972, 15H04781, 15H05059, 15K03417, 15K03982, 15K16181, 15K17232, 15K18174, 15K19241, 15K21266, 15KT0007, 15KT0097, 16H05556, 16K09122, 16K00913, 16K02025, 16K12964, 16K13443, 16K16295, 16K16595, 16K16633, 16K17256, 16K17281, 16K19247, 16K19267, 16K21461, 16K21465, 16KT0014, 17K04305,17K34567, 17K04306, 25253052, 25713027, 26285138, 26460828, 26780328, 18H03018, 18H04071, $18 \mathrm{H} 03047,18 \mathrm{H} 00953,18 \mathrm{H} 00955,18 \mathrm{KK} 0057,19 \mathrm{H} 03901,19 \mathrm{H} 03915,19 \mathrm{H} 03860,19 \mathrm{~K} 04785$, 19K10641,19K11657,19K19818, 19K19455, 19K24060, 19K20909, 20H00557) from JSPS (Japan Society for the Promotion of Science); Health Labour Sciences Research Grants (H26-Choju-Ippan-006, H27-Ninchisyou-Ippan001 H28- Choju-Ippan-002, H28-Ninchisyou-Ippan-002, H29-Chikyukibo-Ippan-001, H30-Jyunkankinado-Ippan-004, 18H04071, 19FA1012, 19FA2001) from the Ministry of Health, Labour and Welfare, Japan; the Research and Development Grants for Longevity Science from Japan Agency for Medical Research and development (AMED) (JP17dk0110027, JP18dk0110027, JP18ls0110002, JP18le0110009, JP20dk0110034, JP20dk0110037), the Research Funding for Longevity Sciences from National Center for Geriatrics and Gerontology (24-17, 24-23, 29-42, 30-30, 30-22, 20-19); Open Innovation Platform with Enterprises, Research Institute and Academia 囚OPERA囚JPMJOP1831هfrom the Japan Science and Technology (JST); a grant from the Japan Foundation For Aging And Health (J09KF00804), a grant from Innovative Research Program on Suicide Countermeasures (1-4), a grant from Sasakawa Sports Foundation, a grant from Japan Health Promotion \& Fitness Foundation, a grant from Chiba Foundation for Health Promotion \& Disease Prevention, the 8020 Research Grant for fiscal 2019 from the 8020 Promotion Foundation (adopted number: 19-2-06), a grant from Niimi University (1915010), and grants from Meiji Yasuda Life Foundation of Health and Welfare. The views and opinions expressed in this article are

those of the authors and do not necessarily reflect the official policy or position of the respective funding organizations.

\section{References}

1. Troeger, C. et al. Estimates of the global, regional, and national morbidity, mortality, and aetiologies of lower respiratory tract infections in 195 countries: a systematic analysis for the Global Burden of Disease Study 2015. Lancet. Infect. Dis.17, 1133-1161 https://doi.org/10.1016/s1473-3099(17)30396-1 (2017).

2. Morimoto, K. et al. The burden and etiology of community-onset pneumonia in the aging Japanese population: a multicenter prospective study. PLoS One.10, e0122247 https://doi.org/10.1371/journal.pone.0122247 (2015).

3. Jain, S. et al. Community-Acquired Pneumonia Requiring Hospitalization among U.S. Adults. N Engl J Med.373, 415-427 https://doi.org/10.1056/NEJMoa1500245 (2015).

4. Torres, A., Peetermans, W. E., Viegi, G. \& Blasi, F. Risk factors for community-acquired pneumonia in adults in Europe: a literature review. Thorax.68, 1057-1065 https://doi.org/10.1136/thoraxjnl-2013-204282 (2013).

5. Shi, T. et al. Global and Regional Burden of Hospital Admissions for Pneumonia in Older Adults: A Systematic Review and Meta-Analysis. J Infect Dis.222, S570-S576 https://doi.org/10.1093/infdis/jiz053 (2020).

6. Clegg, A., Young, J., Iliffe, S., Rikkert, M. O. \& Rockwood, K. Frailty in elderly people. The Lancet.381, 752-762 https://doi.org/10.1016/s0140-6736(12)62167-9 (2013). 
7. Fried, L. P. et al. Frailty in older adults: evidence for a phenotype. J Gerontol A Biol Sci Med Sci.56, M146-156 https://doi.org/10.1093/gerona/56.3.m146 (2001).

8. O'Caoimh, R. et al. Prevalence of frailty in 62 countries across the world: a systematic review and metaanalysis of population-level studies. Age Ageing.https://doi.org/10.1093/ageing/afaa219 (2020).

9. Hewitt, J. et al. The effect of frailty on survival in patients with COVID-19 (COPE): a multicentre, European, observational cohort study. The Lancet Public Health.5, e444-e451 https://doi.org/10.1016/s24682667(20)30146-8 (2020).

10. Lees, C. et al. Frailty Hinders Recovery From Influenza and Acute Respiratory Illness in Older Adults. J Infect Dis.222, 428-437 https://doi.org/10.1093/infdis/jiaa092 (2020).

11. Luo, J., Tang, W., Sun, Y. \& Jiang, C. Impact of frailty on 30-day and 1-year mortality in hospitalised elderly patients with community-acquired pneumonia: a prospective observational study. BMJ Open.10, e038370 https://doi.org/10.1136/bmjopen-2020-038370 (2020).

12. Rothberg, M. B., Haessler, S. D. \& Brown, R. B. Complications of viral influenza. Am J Med.121, 258-264 https://doi.org/10.1016/j.amjmed.2007.10.040 (2008).

13. Satake, S. et al. Validity of the Kihon Checklist for assessing frailty status. Geriatr Gerontol Int.16, 709-715 https://doi.org/10.1111/ggi.12543 (2016).

14. Mochida, Y., Yamamoto, T., Fuchida, S., Aida, J. \& Kondo, K. Does poor oral health status increase the risk of falls?: The JAGES Project Longitudinal Study. PLoS One.13, e0192251 https://doi.org/10.1371/journal.pone.0192251 (2018).

15. Sato, K. et al. Intensity of community-based programs by long-term care insurers and the likelihood of frailty: Multilevel analysis of older Japanese adults. Soc Sci Med.245, 112701 https://doi.org/10.1016/j.socscimed.2019.112701 (2020).

16. Murakami, Y. et al. Factors associated with PPSV23 coverage among older adults in Japan: a nationwide community-based survey. BMJ Open.9, e030197 https://doi.org/10.1136/bmjopen-2019-030197 (2019).

17. Ke, Y., Jiang, J. \& Chen, Y. Social capital and the health of left-behind older adults in rural China: a crosssectional study. BMJ Open.9, e030804 https://doi.org/10.1136/bmjopen-2019-030804 (2019).

18. Fujihara, S. et al. Does Community-Level Social Capital Predict Decline in Instrumental Activities of Daily Living? A JAGES Prospective Cohort Study. Int J Environ Res Public Health.16, https://doi.org/10.3390/ijerph16050828 (2019).

19. Tomioka, K., Kurumatani, N. \& Hosoi, H. Social Participation and the Prevention of Decline in Effectance among Community-Dwelling Elderly: A Population-Based Cohort Study. PLoS One.10, e0139065 https://doi.org/10.1371/journal.pone.0139065 (2015).

20. Shobugawa, Y., Fujiwara, T., Tashiro, A., Saito, R. \& Kondo, K. Social participation and risk of influenza infection in older adults: a cross-sectional study. BMJ Open.8, e016876 https://doi.org/10.1136/bmjopen2017-016876 (2018).

21. Reichard, A., Stransky, M., Phillips, K., McClain, M. \& Drum, C. Prevalence and reasons for delaying and foregoing necessary care by the presence and type of disability among working-age adults. Disabil Health J.10, 39-47 https://doi.org/10.1016/j.dhjo.2016.08.001 (2017).

22. Pansarasa, O. et al. Altered immune system in frailty: Genetics and diet may influence inflammation. Ageing Res Rev.54, 100935 https://doi.org/10.1016/j.arr.2019.100935 (2019). 
23. Bachi, A. L. et al. Increased production of autoantibodies and specific antibodies in response to influenza virus vaccination in physically active older individuals. Results Immunol.3, 10-16 https://doi.org/10.1016/j.rinim.2013.01.001 (2013).

24. Sakamoto, Y. et al. Effect of exercise, aging and functional capacity on acute secretory immunoglobulin A response in elderly people over 75 years of age. Geriatr Gerontol Int.9, 81-88 https://doi.org/10.1111/j.14470594.2008.00502.x (2009).

25. Kimura, F. et al. The Effects of Walking Exercise Training on Immune Response in Elderly Subjects. International Journal of Sport and Health Science.4, 508-514 https://doi.org/10.5432/ijshs.4.508 (2006).

26. Beard, J. L. et al. Iron nutrition in rural home bound elderly persons. J Nutr Elder. 1996; 15(4), 3-19, doi: 10.1300/J052v15n04_02 (1996)

27. Almirall, J., Serra-Prat, M., Bolibar, I. \& Balasso, V. Risk Factors for Community-Acquired Pneumonia in Adults: A Systematic Review of Observational Studies. Respiration.94, 299-311 https://doi.org/10.1159/000479089 (2017).

28. Riquelme, R. et al. Community-acquired pneumonia in the elderly. Clinical and nutritional aspects. Am J Respir Crit Care Med.156, 1908-1914 https://doi.org/10.1164/ajrccm.156.6.9702005 (1997).

29. Ma, H. M., Yu, R. H. \& Woo, J. Recurrent hospitalisation with pneumonia is associated with higher 1-year mortality in frail older people. Intern Med J.43, 1210-1215 https://doi.org/10.1111/imj.12258 (2013).

30. Almirall, J. et al. Oropharyngeal dysphagia is a risk factor for community-acquired pneumonia in the elderly. Eur Respir J.41, 923-928 https://doi.org/10.1183/09031936.00019012 (2013).

31. Nishida, T., Yamabe, K. \& Honda, S. Dysphagia is associated with oral, physical, cognitive and psychological frailty in Japanese community-dwelling elderly persons. Gerodontology.37, 185-190 https://doi.org/10.1111/ger.12455 (2020).

32. Ebihara, S., Ebihara, T. \& Kohzuki, M. Effect of aging on cough and swallowing reflexes: implications for preventing aspiration pneumonia. Lung.190, 29-33 https://doi.org/10.1007/s00408-011-9334-z (2012).

33. Langmore, S. E., Skarupski, K. A. \& Fries, B. E. Predictors of aspiration pneumonia in nursing home residents. Dysphagia.17, 298-307 https://doi.org/10.1007/s00455-002-0072-5 (2002).

34. Gale, S. D., Berrett, A. N., Erickson, L. D., Brown, B. L. \& Hedges, D. W. Association between virus exposure and depression in US adults. Psychiatry Res.261, 73-79 https://doi.org/10.1016/j.psychres.2017.12.037 (2018).

35. Morimoto, S. S. \& Alexopoulos, G. S. Immunity, aging, and geriatric depression. Psychiatr Clin North Am34, 437-449, ix, doi:10.1016/j.psc.2011.02.006 (2011).

36. Kiecolt-Glaser, J. K. \& Glaser, R. Depression and immune function: central pathways to morbidity and mortality. Journal of psychosomatic research.53, 873-876 https://doi.org/10.1016/s0022-3999(02)00309-4 (2002).

37. Ikegami, N. et al. Japanese universal health coverage: evolution, achievements, and challenges. The Lancet.378, 1106-1115 https://doi.org/10.1016/s0140-6736(11)60828-3 (2011).

\section{Supplementary Files}

This is a list of supplementary files associated with this preprint. Click to download.

- Supl.tableSaitolKforScireps.docx 